\title{
Form in examiner comments on MPhil thesis literature reviews in a Ghanaian university
}

\author{
Afful, Joseph Benjamin Archibald $\triangle$ \\ University of Cape Coast, Ghana (jafful@ucc.edu.gh) \\ Tetteh, Gabriel \\ University of Cape Coast, Ghana (gabriel.tetteh3@ stu.ucc.edu.gh)
}

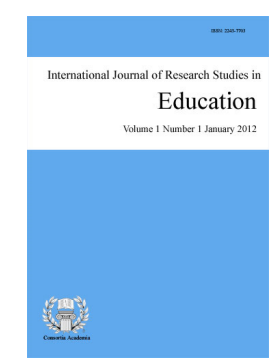

ISSN: 2243-7703 Online ISSN: 2243-7711

Received: 21 October 2021

\begin{abstract}
Higher degree thesis examination has in recent times been garnering considerable attention from researchers from various backgrounds. Thesis examiner's reports constitute an important tool in maintaining standards, improving quality, and building research capacity in higher education worldwide. The study, therefore, seeks to investigate the form of MPhil thesis examination comments on the literature review in a public university in Ghana by paying attention to text length and sequencing of message. Purposive sampling was utilized to select a total of seventy-five MPhil thesis examination reports from four disciplines, namely English, History, Hospitality and Tourism, and Population and Health. The qualitative content analysis was employed, supplemented by some descriptive statistics. Two key findings emerged from the analysis. First, in terms of text length, the MPhil thesis examiners' comments on the literature review utilized on average 114.4 words. Second, the comments were generally sequenced as $(\mathrm{Nu})-\mathrm{P}-(\mathrm{Nu})-\mathrm{Neg}-(\mathrm{Nu})-\mathrm{S}-(\mathrm{Nu})$ pattern where $\mathrm{P}$ (meaning positive), Neg (negative), and $\mathrm{S}$ (suggestion) were constant, with $\mathrm{Nu}$ meaning neutral. These findings, therefore, have implications for the scholarship on thesis examination comments, postgraduate pedagogy.
\end{abstract}

Keywords: faculty, form, literature review, postgraduate students, thesis examiners' reports 


\section{Form in examiner comments on MPhil thesis literature reviews in a Ghanaian university}

\section{Introduction}

Thesis examiners' reports, undeniably, play a crucial role in postgraduate education and research as they constitute an important educational tool in maintaining standards, improving quality, and building research capacity (Bourke, Hattie, \& Anderson, 2004; Kiley, 2009; Kumar \& Stracke, 2011). They provide information on not only research but also on the student, supervisor, and the university (Starfield, Paltridge, McMurtrie, Holbrook, Lovat, Kiley, \& Fairbairn, 2017). Comments in thesis examiners' reports have the potential to help improve the thesis or dissertation. Yet, the content analysis of thesis examiners' reports has largely been limited to studies in Australia (Johnston, 1997; Nightingale, 1984; Pitkethly \& Prosser, 1995), though in several other areas, including Africa, postgraduate education and related practices such as thesis examination are receiving attention.

Focusing on the literature review section, these studies have tended to deal with doctoral theses, a combined data set of doctoral and masters' theses, and in some cases, only masters' theses. First, the thesis literature review is mentioned as a critical component that examiners scrutinize (Johnston, 1997; Winter, Griffiths \& Green, 2000), although methodological and research execution have received more attention in thesis examiners' reports (Delamont, Atkinson, \& Parry, 1997; Nightingale, 1984; Pitkethly \& Prosser, 1995). The decision to focus on the literature review stems from the fact that, as Fitt, Walker, and Leary (2009, p. 3) argue, the literature review "provides a unique vantage point to examine the overall quality of a student's preparation for future work as an independent researcher". The thesis literature review is acknowledged as a rhetorical site that demonstrates postgraduate students' enculturation and literacy in their disciplinary communities (Boote \& Beile, 2005). Holbrook, Bourke, Lovat, \& Dally (2004) found that even though some form of a literature review is included in every $\mathrm{PhD}$ thesis, about one half (53 per cent) of the examiners refer to it in their comments. In most thesis examiners' reports, the thesis examiners' comments on the thesis literature review is restricted to coverage; that is, the depth, breadth, recency, and adequacy of the literature used in the thesis.

One of the earliest studies, Hansford and Maxwell (1993) noted that examiners of master's theses identified that the two most common weaknesses of the literature reviews were students' failure to use recent literature and an inability to critically assess the existing literature. In the work of Holbrook et al. (2004), inaccuracies and utilization and/or theoretical application were mentioned in 23 and 24 per cent respectively, of the comments. Mullins and Kiley's (2002) interview of thirty experienced examiners to determine what they look for in a research thesis further pointed to a relationship between the literature review and the thesis overall, arguing, "The initial impressions of the quality of the thesis are usually formed by the end of the second or third chapter-often by the end of the literature review" (Mullins \& Kiley 2002, p.377). They conclude that a poorly crafted literature review can signal difficulties elsewhere in a thesis. Alternately, a well conceptualized and executed literature review points toward better quality in the overall thesis. Two studies- one Australian and one American-draw upon Mullins and Kiley's confirmatory finding that identifies the importance of the literature review to the doctoral thesis. Holbrook, Bourke, Fairbairn, and Lovat (2007) link the value of the literature review to doctoral practices, establishing that the literature review informs and potentially improves doctoral training outcomes. Drawing on 1310 examiner reports for 501 doctoral candidates across five Australian universities, Holbrook, Bourke, Fairbairn, and Lovat (2007) obtain insight into the examiners' comments on thesis literature review, identifying 'working understanding', 'critical appraisal' of the body of literature, 'connection of the literature to findings', and 'disciplinary perspective' as key indicators of performance in the candidate's use of the literature. They observe that examiners "descriptive comments pertinent to using and applying literature in Australian doctoral theses are predictive of good quality theses and have potential to inform research training" (p. 352).

14 Consortia Academia Publishing (A partner of Network of Professional Researchers and Educators) 
As can be seen from the review, as far as we know, no major study has been conducted in Africa on the form of comments on the literature review in thesis examiners' reports. The closest studies that have come to the present one are Afful (2015) on the evaluative lexis in thesis assessment reports on one hand and Afful (2020) on the discourse of thesis assessment reports in a Ghanaian university on the other hand. Adika (2015) is at best only anecdotal and partial in its treatment of the literature review in thesis examiners' reports, though insightful comments are made on the quality of thesis literature review examined and a resulting pedagogical framework that he formulates. Nkemleke (2011), like Afful (2015). explores the evaluative lexis of, what he describes as, 'pre-viva reports' (or evaluation in pre-defence reports, a mandatory academic report on students' dissertations, written by supervisors of the work) in educational institutions in Cameroon. Other anecdotal evidence of studies on thesis examiners' reports in other African countries include Van Wyk and Lumadi (2009) that affirm the lack of criticality in the thesis literature reviews in a South African university as well as Mulinge and Arasa (2013) whose study of thesis examiners' reports from ten universities across Eastern, Western, and Southern Africa identifies weaknesses such as incoherent reviews, inability to identify areas of contestation and gaps, plagiarism, and poor referencing.

As can be seen from the review, there is an emerging interest being shown by scholars and researchers in Africa in thesis examination practices, in general, and the content analysis of thesis examination reports, in particular. Welcoming as this trend is, we observe that it is still in its nascent stage. As far as we know, no extensive study has been conducted in Africa on comments on the literature review in thesis examiners' reports in a Ghanaian public university. The present research, thus, aims to investigate MPhil thesis examiner comments in order to obtain insights into the form in which examiners present their comments on the literature review as a way of widening the horizon of such research. The specific questions formulated for the present study are presented below:

$>\quad$ What is the text length of comments made by examiners on MPhil thesis literature reviews in four selected departments?

$>$ How are comments made by examiners on MPhil thesis sequenced in the four selected departments?

Both questions relate to the form of the content of thesis examiners' comments, given that the form in which a message is presented has implications for effective communication in a given interactive situation (here, postgraduate education). It is important to obtain answers to the question above so that we understand how examiners in under-researched areas such as Ghana structure their comments and reflect on the appropriateness and sufficiency of current practices. The findings to these questions may widen the scope of examiner comments research.

\section{Methods}

\subsection{Educational setting and research design}

The study was conducted in University of Cape Coast (UCC), one of the public universities in Ghana. About four years ago, UCC went collegiate, continuing its teaching and learning as well as research through five colleges and over 80 departments. It was chosen because of the researchers' affiliation and, more importantly, because in the last two decades, it has been paying serious attention to postgraduate education in response to both national needs and global imperatives in terms of ensuring increase in graduate numbers and quality of its students and their theses. It aims to achieve ten percent graduate population out of the total number of students, which stands at about sixty thousand students. UCC carries out its mandate of delivering graduate programs from the master's to the doctoral level in several departments through the School of Graduate Studies in both the regular and alternative modes. However, the course work master's program remains the only program organized through the alternative modes, sandwich and distance. 
At the University of Cape Coast (UCC), a public university in Ghana, as in several universities worldwide, writing a research report, labeled as 'thesis', is an essential requirement for graduation. In the present study, the terms 'thesis' and 'dissertation' are interchangeably used. According to the School of Graduate Studies at UCC, postgraduate research students are required to submit a thesis within a chosen field of study. It is widely acknowledged that the skills, knowledge, and understandings required for disciplined scholarly enquiry are best acquired by the student through undertaking research in a defined field (Hyland, 2005, 2012; Ridley, 2011). Given the anxiety with which postgraduate research students approach thesis writing, the comments of examiners can allay such fears when they (students) are made aware that they have been successful by way of having adhered to disciplinary epistemologies, values, ethos, and practices in terms of conducting and reporting one's research.

Thesis examiners ultimately make recommendations as to the fate of the thesis. In UCC, the recommendation is a choice of one of the following options: accept the thesis as submitted; accept the thesis with required or invited minor corrections; accept subject to required, more major corrections; require that the thesis be revised and resubmitted for further examination; and fail. When examiner recommendations differ, as in one passing the thesis and the other failing it, the decision awaits the recommendation of a third examiner as a compromise between the two positions. Unlike in Australia (Bourke \& Holbrook, 2013) and other settings, thesis examination in Ghana is not the sole assessment measure taken for research candidatures, there being also an oral examination or viva voce.

Examiners in University of Cape Coast, as in other universities elsewhere (Joyner, 2003), are chosen and approved on the basis of their expertise, qualification, and experience in the subject area of the thesis as well as their availability (Bao \& Leikin, 2013). Examiners are ordinarily mandated, according to Holbrook, Bourke, Fairbairn, and Lovat (2014, p. 986) to judge "both the potential of the researcher and the quality of the research". In order to do this effectively, examiners may be guided by a set of criteria supplied by requesting universities; however, as Mullins and Kiley (2002, p. 380) have shown, experienced examiners do not necessarily follow the "institution-specific criteria" in making judgements about thesis quality. Each examiner writes an independent report on the thesis, the text length of which depends on the level of program (masters' or doctoral).

Drawing on similar studies such as Holbrook et al. (2007) and Kumar and Stracke (2011), we used a content analysis methodology. The choice of the qualitative content analysis enables attention to be paid to the naturally occurring data (here, the examiners' comments), which are not medicated through any means. Such data is not reducible to a statistical form for purpose of analysis. The chosen research approach thus enables a close reading of the text of written assessment reports on thesis literature reviews with the view to obtaining answers to the research question. This qualitative approach was then complemented by some descriptive statistics.

\subsection{Data and data collection procedure}

Purposive sampling was utilized to select a total of seventy-five thesis examination reports from four disciplines, namely English, History, Hospitality and Tourism, and Population and Health. Each department provided twenty MPhil thesis examiners' reports written in the last decade, with the exception of the Department of History, which could provide only fifteen examiners' reports. Only reports which contained continuous writing rather than writing in bullet form. Again, comments in, at least, two sentences were selected. In all, the sample size for each department depended on the extent to which the selection criteria were met. The overall sample size for the study was considered adequate, given the time within which the research needed to be conducted and findings reported.

Photocopies of the original reports on each thesis were obtained from four disciplines at University of Cape Coast: English, History (Faculty of Arts) and Population and Health, and Hospitality and Tourism (Faculty of Social Sciences). They were either scanned electronically or re-typed, where necessary. When scanned, the data were archived, and an electronic copy formatted, using a standard set of procedures. The scanned copy was

16 Consortia Academia Publishing (A partner of Network of Professional Researchers and Educators) 
checked against the original for errors caused by scanning. Some minor typographic errors or abbreviations that might have existed in the originals were also corrected in so far as they did not change the sense of the report. The latter step was necessary in order to prevent typographical errors from impeding authenticity and accuracy. Ultimately, these cautionary steps were taken to ensure validity and reliability.

Further, to ensure ethical consideration in the research, we sought consent for the use of the thesis examiners from the participating departments. Also, confidentiality of the data was given attention, given the occluded nature of the data. Candidates whose theses were examined and the thesis examiners whose comments are under study were duly anonymized, using appropriate codes, in the analysis, interpretation, and discussion of data. The comments that are presented as illustrative materials remain unedited to ensure that the data is not sanitized; thus maintaining their naturalness and authenticity.

\subsection{Data analysis}

The core content categories drew on the existing thesis literature review rubrics (e.g. Boote \& Beile, 2005; Cooper, 1985; and Holbrook et al., 2007) and used them in the course of establishing inter-rater agreement, through peer review, iteration across the data. Because high inter-rater agreement is required during the core coding stage (we aimed for and achieved 80 per cent agreement between two coders who were $\mathrm{PhD}$ students in Applied English Language Studies), detailed coding notes with examples from the reports were developed, used, and progressively refined after an orientation session had been organized for the two PhD students. The texts we captured were quantified and explored for patterns, themes, and relationships while looking for possible irregular information. The thesis examiners' comments on thesis literature review are presented as illustrated texts unedited in the next section of the paper.

\section{Findings and Discussion}

In this section, results of the content analysis of the data set are presented and discussed in respect of the two questions in two parts. Thus, the first presents quantitative information while the second focuses on the qualitative part.

\subsection{Quantitative evidence}

Table 1 presents the results on the text length of the 75 theses reports across the four disciplines in the study.

\section{Table 1}

Text Length of Thesis Examiners' Reports (TERs) on LR

\begin{tabular}{|c|c|c|c|}
\hline Departments & Total (Words) & Percentage $\%$ & Average \\
\hline English (ELRC) & 2388 & 28.3 & 119.4 \\
\hline History (HLRC) & 2124 & 25.2 & 141.6 \\
\hline Hospitality \& Tourism (TLRC) & 1626 & 19.2 & 81.3 \\
\hline Population and Health (PLRC) & 2305 & 27.3 & 115.3 \\
\hline TOTAL & 8443 & 100 & 457.6 \\
\hline
\end{tabular}

The results summarized in Table 1 show that examiners from the Department of English gave more space and, thus, attention in terms of number of words, to addressing issues in candidates' literature reviews with a total of 2388 (an average of 119.4) words. Thesis examiners reports from the Department of Hospitality and Tourism had the least text length, a total of 1626 (an average of 81.3) words. In essence, considering the averages of the four data sets from the participating departments, one can conclude that thesis examiners' reports on the literature review section normally contain about 114.4 words-an average of the sum of all averages which is 457.6 .

The following data samples taken from the four departments exemplify the average text length of 114.4 words reported in this study: 
Afful, J. B. A., \& Tetteh, G.

\section{Extract 1}

A wide range of relevant literature, including geriatric health assessment, psycho-social determinants of health and eye diseases were reviewed to provide insight on the topic He amply demonstrated good knowledge of pertinent literature. He would do well to address some pockets of speculative writing. Adaptation of the Visual functioning model of Coleman et al. (2008) for the study is acceptable. However, since no framework is water-tight, the model could have been adapted to reflect the farming environment of the tropics. The candidate could have gone further to provide a critique of the framework and also justify why he settled for its use in his study. (PLRC 16)

\section{Extract 2}

Literature Review: References cited were current, and adequate and relevant. References covered wide areas such as the level of education of women, and other socio-demographic variables that influence post-natal clinic attendance. Conceptual framework: The Titaley et al. (2009) and later 2010 model were adapted for the study because some variables are not available in the GDHS document and not in line with the objectives of the study. The framework was reviewed critically by the researcher by assessing the strength and weaknesses of the framework. The framework sufficiently guided the study. However, Fig 6 p. 46 could not be identified in the document. The researcher should cross-check. (PLRC 6)

\section{Extract 3}

The candidate has demonstrated awareness of the available literature on the subject matter. The literature review is comprehensive and addresses the pertinent issues relating to the objectives of the study. However, on page 20, she indicates that souvenirs have 'sign value' and 'use value'. I expected some explanation as to what those terms mean. Also, she presents an adaptation of the consumer decision-making model by eliminating the fifth phase of the model even though that is not conceptual framework. I think she has to present the original model with all the five phases since at this stage she was only reviewing the model, then she can adapt it as she has done in her conceptual framework. (TLRC 11)

\section{Extract 4}

The study is not adequately informed by empirical works and has to be improved. Four competing theoretical frameworks - the Needs-Function model of tourism distribution, the place of the tour operator in the distribution system, the structure of the US travel intermediation and the distribution function for package were considered in the work. At the end the distribution was adopted to guide the study. Empirical works reviewed in this study is inadequate and have to be revisited. (TLRC 7)

\section{Extract 5}

The candidate shows a good knowledge of the relevant works on the history of Ghana and how they relate to biographical studies in general in Ghana and how they do not relate in particular to his subject matter. He did not, however, make use of biographical studies that exist in the History Department on Ghanaian personalities such as Otumfuo Sir Agyeman Prempeh II, Victor Owusu and President Limann. These could have enriched and guided him in his study of Sir Emmanuel Charles Quist. Theoretical and conceptual frameworks are not used in history and in line with this, the candidate has no theoretical or conceptual framework in his dissertation. (HLRC 9) 
Extract 6

The candidate indicated that historical studies on the Bassari in northern Ghana were few, cursory and fragmentary, and that is reflected in the literature reviewed by him. The candidate identified three historical periods: the colonial period (1890's - 1957-60); the independence period (1057-60 - 1980's); and finally current research period (1990s - 2012). He identified for each period literature about the Bassari in both Ghana and Togo and acquired translations of French texts. In this era as elsewhere, the candidate provided exceptional knowledge of his material and his commitment to research. (HLRC 1)

\section{Extract 7}

The main observation I can make relates to the fact that there is no review at all. The candidate has read extensively, especially the texts on genre studies. Indeed, the information on genre and Systemic Functional linguistics is detailed and quite relevant. But, there are some problems: The candidate merely provides a summary of the ideas in the read texts. There is no proper coherent structure in the presentation of the ideas. The information is poorly organized. The candidate does not relate what he is reporting to the study. Thus, it is difficult to see what relevance the literature has to the study. Interestingly, the section which reviews "empirical studies" is far better presented. (ELRC 7)

\section{Extract 8}

The literature review section presents a comprehensive account of studies undertaken on different aspects of Ghanaian English as well as studies on acceptability. There is a good explanation and review of the notion of Ghanaian English. The review covers literature on studies undertaken by scholars who support the existence of Ghanaian English. The candidate shows familiarity with many studies related to the area she is investigating. She also offers a detailed discussion of works on acceptability of World Englishes. Here she reviews works that address phonological acceptability, lexico-graphical acceptability, pragmatic acceptability and the acceptability of Ghanaian English. (ELRC 13)

The samples (1-8) contain evaluation of the students' attempt at presenting the conceptual terrain for the different studies. In other words, assessors provided both negative and positive comments, referred to by Hyland and Hyland (2001) as 'pill' and 'sugar' respectively. Extracts 1, 2, 3. 5, and 7 combined both negative and positive comments whereas Extracts 4 and 6 were solely negative and positive comments respectively. Thus, while some of the TECs are more critical, thus containing negative comments, others contained only positive comments. It can be said that the illustrative texts show that examiners often presented more nuanced comments, depicting their own of sense of criticality and using appropriate evaluative lexis in consonance with their disciplinary ethos.

In fact, the average text length of thesis examiners' comments shown in this study receives support from the findings of Holbrook et al. (2007) who, after investigating examiners' comments on the literature review in $\mathrm{PhD}$ theses among five Australian universities, aver, "Examiners on average devote about $10 \%$ of the examination report on the way the candidate has reviewed the literature" (p. 342). One can still appreciate that $10 \%$ is relatively small and may, therefore, not be significantly different from the average of 114.4 words observed in the study here. In another study, Holbrook, et al. (2004) found that only $9 \%$ of the theses reports were usually "[d]evoted to discussion of all aspects of the literature review including the breadth and depth of coverage as well as errors in citation or referencing” (p. 109).

In the second part of our discussion on form, we report and discuss the findings on sequencing of the presentation of summative and formative comments (see earlier discussion on theses). Examiners usually make 
Afful, J. B. A., \& Tetteh, G.

judgements or evaluative comments (whether positive, negative, neutral or suggestion) regarding the theses they assess and give their assessment feedback on how students can make up for the weaknesses identified-be it examiners of MPhil or PhD theses (Golding, Sharmini, \& Lazarovitch, 2014; Holbrook et al., 2004; Kumar \& Stracke, 2011; Prieto, Holbrook \& Bourke, 2016). What is, however, often unclear in the literature is the sequence in which such evaluative comments are usually presented by examiners, which is very important taking into the consideration the effects that examiners' comments are likely to have on recipients (Kumar \& Stracke, 2011).

Table 2 presents the results of analyses undertaken on the data gathered across the four disciplines in respect of sequencing of the comments.

Table 2

Sequencing patterns of summative and formative comments in thesis examiners' reports across four disciplines

\begin{tabular}{|c|c|c|c|c|c|c|c|}
\hline \multicolumn{2}{|c|}{ ENGLISH } & \multicolumn{2}{|l|}{ HISTORY } & \multicolumn{2}{|c|}{$\begin{array}{c}\text { HOSPITALITY \& } \\
\text { TOURISM }\end{array}$} & \multicolumn{2}{|c|}{$\begin{array}{c}\text { POPULATION AND } \\
\text { HEALTH }\end{array}$} \\
\hline Sequence & Total & Sequence & Total & Sequence & Total & Sequence & Total \\
\hline $\mathrm{P} \rightarrow \mathrm{Neg}$ & 7 & $\mathrm{P} \rightarrow \mathrm{Neg}$ & 2 & $\mathrm{P}$ & 10 & $\mathrm{P}$ & 4 \\
\hline $\mathrm{P}$ & 2 & $\mathrm{P} \rightarrow \mathrm{Nu} \rightarrow \mathrm{P}$ & 2 & $\mathrm{P} \rightarrow \mathrm{Neg} \rightarrow \mathrm{S}$ & 2 & $\mathrm{P} \rightarrow \mathrm{Neg}$ & 3 \\
\hline $\mathrm{Nu} \rightarrow \mathrm{P} \rightarrow \mathrm{Neg}$ & 2 & $\mathrm{P} \rightarrow \mathrm{Nu} \rightarrow \mathrm{P} \rightarrow \mathrm{Nu}$ & 2 & $\mathrm{P} \rightarrow \mathrm{Nu} \rightarrow \mathrm{Neg}$ & 1 & $\mathrm{P} \rightarrow \mathrm{Neg} \rightarrow \mathrm{S}$ & 2 \\
\hline $\mathrm{P} \rightarrow \mathrm{Nu} \rightarrow \mathrm{P}$ & 2 & $\mathrm{P} \rightarrow \mathrm{Neg} \rightarrow \mathrm{Nu}$ & 1 & $\mathrm{P} \rightarrow \mathrm{Neg} \rightarrow \mathrm{Nu} \rightarrow \mathrm{Neg} \rightarrow \mathrm{Nu}$ & 1 & $\mathrm{P} \rightarrow \mathrm{Nu} \rightarrow \mathrm{P} \rightarrow \mathrm{Neg}$ & 2 \\
\hline $\mathrm{Neg} \rightarrow \mathrm{P} \rightarrow \mathrm{Neg} \rightarrow \mathrm{P}$ & 1 & Neg & 1 & $\mathrm{P} \rightarrow \mathrm{Neg} \rightarrow \mathrm{S} \rightarrow \mathrm{Neg} \rightarrow \mathrm{S}$ & 1 & $\mathrm{P} \rightarrow \mathrm{S} \rightarrow \mathrm{Neg} \rightarrow \mathrm{P}$ & 1 \\
\hline $\mathrm{P} \rightarrow \mathrm{Nu} \rightarrow \mathrm{P} \rightarrow \mathrm{Nu}$ & 1 & $\mathrm{Nu} \rightarrow \mathrm{P}$ & 1 & $\mathrm{P} \rightarrow \mathrm{Neg}$ & 1 & $\mathrm{Nu} \rightarrow \mathrm{P} \rightarrow \mathrm{Neg}$ & 1 \\
\hline $\mathrm{Nu} \rightarrow \mathrm{P}$ & 1 & $\mathrm{P} \rightarrow \mathrm{Nu} \rightarrow \mathrm{P} \rightarrow \mathrm{Neg} \rightarrow \mathrm{S} \rightarrow \mathrm{Nu}$ & 1 & $\mathrm{P} \rightarrow \mathrm{Neg} \rightarrow \mathrm{S} \rightarrow \mathrm{Neg} \rightarrow \mathrm{S} \rightarrow \mathrm{Nu}$ & 1 & $\mathrm{P} \rightarrow \mathrm{Neg} \rightarrow \mathrm{S} \rightarrow \mathrm{Neg}$ & 1 \\
\hline Neg & 1 & $\mathrm{Neg} \rightarrow \mathrm{Nu} \rightarrow \mathrm{Neg} \rightarrow \mathrm{S} \rightarrow \mathrm{Nu}$ & 1 & $\mathrm{Neg} \rightarrow \mathrm{Nu} \rightarrow \mathrm{Neg}$ & 1 & $\mathrm{Nu} \rightarrow \mathrm{P}$ & 1 \\
\hline $\mathrm{P} \rightarrow \mathrm{Neg} \rightarrow \mathrm{S}$ & 1 & $\mathrm{P} \rightarrow \mathrm{Neg} \rightarrow \mathrm{S} \rightarrow \mathrm{Nu}$ & 1 & $\mathrm{Nu} \rightarrow \mathrm{Neg} \rightarrow \mathrm{S}$ & 1 & $\mathrm{P} \rightarrow \mathrm{Nu} \rightarrow \mathrm{Neg} \rightarrow \mathrm{S}$ & 1 \\
\hline $\mathrm{P} \rightarrow \mathrm{S}$ & 1 & $\mathrm{P} \rightarrow \mathrm{Nu}$ & 1 & $\mathrm{P} \rightarrow \mathrm{Nu}$ & 1 & $\mathrm{Nu} \rightarrow \mathrm{S}$ & 1 \\
\hline \multirow[t]{3}{*}{$\mathrm{P} \rightarrow \mathrm{Nu} \rightarrow \mathrm{P} \rightarrow \mathrm{Neg}$} & & $\mathrm{P}$ & 1 & & & $\mathrm{P} \rightarrow \mathrm{Neg} \rightarrow \mathrm{P} \rightarrow \mathrm{Neg}$ & 1 \\
\hline & & $\mathrm{P} \rightarrow \mathrm{Neg} \rightarrow \mathrm{S} \rightarrow \mathrm{Neg} \rightarrow \mathrm{P} \rightarrow \mathrm{Nu}$ & 1 & & & $\mathrm{P} \rightarrow \mathrm{Neg} \rightarrow \mathrm{S} \rightarrow \mathrm{Neg} \rightarrow \mathrm{S}$ & 1 \\
\hline & & & & & & $\mathrm{P} \rightarrow \mathrm{Neg} \rightarrow \mathrm{P}$ & 1 \\
\hline
\end{tabular}

As can be seen from the table (2), there were some differences in the number of occurrences of the various sequencing patterns across the disciplines in respect of TECs. Thus, whereas, for English, $\mathrm{P} \rightarrow \mathrm{Neg}$ sequence occurred 7 times and $\mathrm{Nu} \rightarrow \mathrm{P} \rightarrow \mathrm{Neg}$; $\mathrm{P}$; and $\mathrm{P}-\mathrm{Nu}-\mathrm{P}$ occurred 2 times each - the other sequences for ELRCs occurring once each - for History, it is $\mathrm{P} \rightarrow \mathrm{Nu} \rightarrow \mathrm{P} ; \mathrm{P} \rightarrow \mathrm{Nu} \rightarrow \mathrm{P} \rightarrow \mathrm{Nu}$ and $\mathrm{P} \rightarrow \mathrm{Neg}$; (occurred 2 each) that dominate, with the others appearing once. Concerning Hospitality and Tourism and Population and Health, whereas, for the former, $\mathrm{P}$ (occurring 10 times) and $\mathrm{P} \rightarrow \mathrm{Neg} \rightarrow \mathrm{S}$ (occurring twice) dominate with the other patterns appearing once, for the latter, it is $\mathrm{P}$ (4 times); $\mathrm{P} \rightarrow \mathrm{Neg}$ (3 times); $\mathrm{P} \rightarrow \mathrm{Neg} \rightarrow \mathrm{S}$ and $\mathrm{P} \rightarrow \mathrm{Nu} \rightarrow \mathrm{Neg} \rightarrow \mathrm{S}$ (twice each) that dominate the rest occurring singly. It is clear then that $\mathrm{P} \rightarrow \mathrm{Neg}, \mathrm{P} \rightarrow \mathrm{Nu} \rightarrow \mathrm{P}$ and $\mathrm{P}$ are dominant sequencing patterns among ELRC and HLRC and TLRC and PLRC respectively, suggesting disciplinary influences. Samples of these sequencing patterns in the TERs are shown below:

\section{Extract 9}

$\boldsymbol{P}=$ There is evidence from the thesis to show that the candidate has read extensively on the two pillars of the thesis - modality and power. Neg $=$ However, the major problem is that there is no attempt to show the relevance of the literature to the topic under discussion. I have raised several such queries in the text. (cf pp. 1-5, 19, 23-30, 34-42, 44-45, 48, 52, 56-59) Secondly, the candidate sounds repetitive in many portions of the text. There are problems with the coherent presentation of the literature review. The result is that the candidate happens to jump from one idea to another. He keeps on repeating ideas which have been earlier mentioned. In addition, we do not hear the candidate's voice at all. All that he has done is to report on what others have said. There is no effort to add his own views on what he has read. (ELRC 16)

\section{Extract 10}

$\boldsymbol{P}=$ The candidate demonstrated adequate knowledge of literature on the History of Ghana generally. Neg $=$ The only shortcoming of the candidate was his failure to examine the works of 
Dr Kwabena Adu Boahen and Dr Kwamr Kwarteng which are specifically on Brong Ahafo. Besides, out of the so many published works on colonization of the Gold Coast by the British, the candidate relied only on the account of Lord Hailey, "An African Survey' Revised Edition, (Oxford University Press, 1957) without acknowledging or referencing the other. (HLRC 11)

\section{Extract 11}

$\boldsymbol{P}=$ The candidate demonstrated in-depth and comprehensive knowledge of the study topic and developed a conceptual framework based on the literature surveyed. This aspect of the study has been well fashioned out and discussed in clear and unambiguous manner. (HLRC 14)

\section{Extract 12}

$\boldsymbol{P}=$ The candidate has provided a thorough and comprehensive review of the pertinent literature as well as an adequate and appropriate conceptual framework to guide data analysis. In view of the relevant literature he discussed both the strength and weaknesses of some of the studies and this is highly commendable. (PLRC 15)

In explaining the differences realized in the dominant sequencing patterns of each of the four departments' thesis examiners' reports, one wonders whether students from the Department of English generally performed poorly in handling the literature review section in their theses or that examiners of students of English were overly critical of their students. Of the two possibilities given above, readers are likely to accept the latter, especially, when they uncover that, comparably, examiners from the Department of English comment on more performance indicators in students' theses than examiners of students from the other departments (Afful \& Tetteh, under review). In that study (that is, Afful \& Tetteh) which addresses on the key performance indicators that examiners focus on when commenting on thesis literature reviews revealed that examiners of ELRCs touched on five to six key indicators while those of HLRCs, TLRCs and PLRCs recorded 0, 1 and 3 respectively. Although Holbrook et al. (2007) focused on examiners reports on the LR section, which examiners across the four disciplines exercised much criticality did not feature in their study.

Again, as can be seen in Table 2, although theses examiners of English appear to be more critical than their peers, they were less likely to offer suggestions to aid students in revising their literature review for final submission. There are only 2 instances of suggestion for English as compared to the 4, 6 and 7 instances for History, Hospitality and Tourism and Population and Health respectively. Kumar and Stracke (2011, p. 217), in agreement with Starfield et al. (2017), note that examiners' assessments of theses are not final as it is the case with end-of-semester examinations, but the "[c]andidate is given the opportunity to close any gap identified by the examiners" and for which reason the "[c]andidate relies on the feedback offered by examiners" to revise their work for final submission. Therefore, students of English face much difficult task of inferring from the negative comments made from examiners what should constitute the needed recommendations and changes.

In essence, in terms of sequencing, Table 2 shows that the dominant pattern across all four disciplines is $(\mathrm{Nu})$ $\rightarrow \mathrm{P} \rightarrow(\mathrm{Nu}) \rightarrow \mathrm{Neg} \rightarrow(\mathrm{Nu}) \rightarrow \mathrm{S} \rightarrow(\mathrm{Nu})$. This means that while $\mathrm{P}$, Neg, S are more likely to occur in the positions identified, $\mathrm{Nu}$ is more likely to alternate between the others. One realizes from the data that examiners usually use neutral voice to provide evidence for the positive and negative evaluative judgements made by examiners, leading to suggestions from them (examiners). Kumar and Stracke (2011), thus, confirm that "[c]ritical assessments were always well substantiated with evidence from the thesis" (p. 214). The following are examples of such use of neutrals in the current data:

\section{Extract 13}

There is a good explanation and review of the notion of Ghanaian English $(P)$. The review covers literature on studies undertaken by scholars who support the existence ... and those who argue against ... (Nu)" (ELRC 13) 
Afful, J. B. A., \& Tetteh, G.

Extract 14

The candidate's knowledge of pertinent literature on the area studied is good (P). Among the works she reviewed include... (Nu) (HLRC 15)

\section{Extract 15}

References cited were current, adequate and relevant $(P)$. References covered wide areas such as the level of education of women ... (Nu) (PLRC 6)

\section{Extract 16}

In this regard, the analysis on pages 149 and 159 need to be reconsidered since it has no basis (S). In the literature review . . socio-demographic characteristics are always related to overall service quality and not the individual dimensions (Nu)” (TLRC 16)

As can be seen from the above extracts, the neutral comments tended to be descriptive, often preceded by positive comments to compliment and make the student feel good, courtesy of Robin Lakoff's maxim.

\section{Conclusion and Implications}

This study sought to investigate the form of the thesis examination comments on the literature review section of MPhil theses written by students in a Ghanaian university, considering the amount of space devoted to the literature and the sequencing of information presented. To accomplish this task, seventy-five thesis examination reports were obtained from four departments, two each from the Faculty of Arts and the Faculty of Social Sciences, after observing the necessary ethical protocols. The qualitative content analysis, deemed to be appropriate and supported by descriptive statistics, was used to derive the findings. The key findings and implications are next discussed.

First, it was revealed that the average text length for the literature review in the thesis examiners' reports was 114.4 words. Closely related to this was the observation that examiners from the Department of English tended to deploy more words in their comment, with the least from examiners from Hospitality and Tourism. As already alluded to, the longer English texts may be due to their attempt to include more performance indicators (such as connection between present and past studies, criticality, evaluative judgements, etc.) Second, evaluative judgements and feedback as comments on the literature reviews in the thesis examiners' reports took the following sequencing pattern: $(\mathrm{Nu}) \rightarrow \mathrm{P} \rightarrow(\mathrm{Nu}) \rightarrow \mathrm{Neg} \rightarrow(\mathrm{Nu}) \rightarrow \mathrm{S} \rightarrow(\mathrm{Nu})$ pattern where $\mathrm{P}$, Neg and $\mathrm{S}$ are constant. Thus, taking into consideration the importance of positive feedback-being described as a doze of motivation - (Kumar \& Stracke, 2011) - one may conclude that thesis examiners seek to first motivate students before criticizing their work, an approach which is likely to make students see negative comments as constructive rather than destructive.

The study contributes to the scholarship on thesis examination reports, as much of the literature on thesis examination reports (Golding et al., 2014; Holbrook et al., 2004a, b; Holbrook et al., 2007; Prieto et al., 2016) had paid less attention to the pattern or sequence in which such judgements on students' output are presented. Earlier studies by Holbrook and her team of researchers from Australia had paved the way for close textual analysis of thesis examiners' reports by identifying the following researchable issues: 1) report organization, 2) examiner and process, 3) assessable areas covered, 4) dialogic elements, and 5) evaluative elements. In general, therefore, the present study speaks to the dimension of assessable areas covered in thesis examiners' reports; in this study, it is the literature review. Even more interesting is the fact that unlike several previous studies, the study presents the sequencing pattern for thesis examiners' reports, showing how Ghanaian examiners typically sequence their report on the literature review as: $(\mathrm{Nu})-\mathrm{P}-(\mathrm{Nu})-\mathrm{Neg}-(\mathrm{Nu})-\mathrm{S}-(\mathrm{Nu})$ pattern where $\mathrm{P}$ (meaning positive), Neg (negative), and S (suggestion). It can also be said that previous studies had been conducted from mainly non-African contexts. The findings from the study conducted in an otherwise under researched 
provenance help to widen the scope of study and adds to the extant scholarship.

The second implication concerns postgraduate pedagogy. Both students and faculty, who are continuously engaged with the business of writing and examining theses respectively, can enhance their different practices by considering thesis examiners' comments as not a final judgment but as an assessment and feedback comment which requires patience in deconstructing it and, more importantly, making the necessary revision for final submission after the candidate has defended the thesis. Faculty require as much care as possible in the construction of thesis examiners' comments to make the revision to the thesis less exacting for students.

The third implication relates to the professionalization of the writing of thesis examiners' comments as it has always been assumed that $\mathrm{PhD}$ holders do not require any training in undertaking thesis examination. As part of the professionalization of faculty in postgraduate education, there is the need for examiner training, as advocated by Cryer and Mertens (2003) and Sankaran, Swepson, and Hill (2005). This training to be organized for, especially, fresh examiners will allow examiners to reflect on their examining practices and embrace, more willingly, their dual role as assessor and feedback provider, with the ultimate aim of enhancing the quality of the thesis. This will also allow for a better understanding of the educational role of supervisors and examiners (Kumar \& Stracke, 2011; Stracke, 2010; Stracke \& Kumar, 2010).

Notwithstanding these implications, there are limitations in the study that call for further research. A researcher can consider aspects proposed by Holbrook and her colleagues such as the dialogic elements and evaluative elements in thesis examiners' comments on the literature review section. Drawing on Holbrook et al. (2004a, b), further research could be carried out into the other categories of thesis examiners' reports on masters' and doctoral theses in Ghanaian universities, in particular, and African universities, in general. A larger sample of postgraduate thesis examiners' reports at both Master's and PhD level, from various disciplines and from other countries, will allow for more insights and more robust findings. Further research can employ ethnography to engage the examiners to ascertain reasons for the form of thesis examiners' comments on the thesis literature review, in terms of text length and sequencing of the comments that they employ.

\section{References}

Adika, G. S. K. (2015). Credibility and accountability in academic discourse: Increasing the awareness of Ghanaian graduate students. Practice and Theory in Systems of Education, 10(3), 227-244.

Afful, J. B. A., \& Tetteh, G. (under review). Focus in examiner comments on MPhil thesis literature reviews.

Afful, J.B.A. (2020). The discourse of thesis assessment reports in a disciplinary community at the University of Cape Coast: An exploratory study. International Journal of Language, Literature and Gender Studies, 9(1), 117-134.

Bao, D., \& Leikin, I. (2013). Graduate student scholars embarking on research: Assessment of masters' minor theses in an Australian university. Journal of Science Ho Chi Minh Open University, 1(6), 35-44.

Boote, D. N., \& Beile, P. (2005). Scholars before researchers: On the centrality of the dissertation literature review in research preparation. Educational Researcher, 34(6), 3-15.

Bourke, S., \& Holbrook, A. (2013). Examining PhD and research master's theses. Assessment \& Evaluation in Higher Education, 38, 407-416.

Bourke, S., Hattie, J., \& Anderson, L. (2004). Predicting examiner recommendations on PhD theses. International Journal of Educational Research, 41(2), 178-194.

Cooper, H. M. (1985). A taxonomy of literature reviews. Annual meeting of the American Educational Research Association. Chicago, ERIC Document Reproduction Services No. ED254541.

Cryer, P., \& Mertens, P. (2003). The PhD examination: Support and training for supervisors and examiners. Quality Assurance in Education, 11(2), 92-99.

Delamont, S., Atkinson, P., \& Parry, O. (1997). Supervising the PhD: a guide to success Buckingham: Open University Press.

Fitt, M. H., Walker, A.E., \& Leary, H. M. (2009). Assessing the quality of doctoral dissertation literature 
reviews in Instructional Technology. Paper presented at the annual meeting of the American Educational Research Association, San Diego, CA.

Golding, C., Sharmini, S., \& Lazarovitch, A. (2014). What examiners do: what thesis students should know. Assessment \& Evaluation in Higher Education, 39(5). https://doi.org/10.1080/02602938.2013.859230

Hansford, B. C., \& Maxwell, T. W. (1993). A master's degree program: Structural components and examiners' comments, Higher Education Research and Development, 12(2), 171-187.

Hart, C. (1998). Doing a literature review. London: Sage.

Holbrook, A., Bourke, S., Fairbairn, H. \& Lovat, T. (2014). The focus and substance of formative comment provided by PhD examiners, Studies in Higher Education, 39(6), 983-1000. https://doi.org/10.1080/03075079.2012.750289

Holbrook, A., Bourke, S., Fairbairn, H., \& Lovat, T. (2007). Examiner comment on the literature review in PhD theses. Studies in Higher Education, 32(3). 337-356.

Holbrook, A., Bourke, S., Lovat, T., \& Dally, K. (2004a). Qualities and characteristics in the written reports of doctoral thesis examiners. Australian Journal of Educational \& Developmental Psychology, 4, 110-129.

Holbrook, A., Bourke, S., Lovat, T., \& Dally, K.(2004b). Investigating PhD Thesis Examination Reports. International Journal of Educational Research, 41(2), 98-120.

Hyland, F., \& Hyland, K. (2001). Sugaring the pill: Praise and criticism in written feedback. Journal of Second Language Writing, 10, 185-212.

Hyland, K. (2005). Representing readers in writing: student and expert practices. Linguistics and Education, 16, 363-377.

Hyland, K. (2012). Disciplinary identities: Individuality and commonality in academic discourse. Cambridge: Cambridge University Press.

Johnston, S. (1997). Examining the examiners: An analysis of examiners' reports on doctoral theses. Studies in Higher Education, 22(3), 333-348.

Kiley, M. (2009). 'You don't want a smart Alec': Selecting examiners to assess doctoral dissertations. Studies in Higher Education, 34(8), 889-903.

Kumar, V., \& Stracke, E. (2011). Examiners' reports on theses: Feedback or assessment? Journal of English for Academic Purposes, 10(4), 211-222.

Mullins, G., \& Kiley, M. (2002). 'It's a PhD, not a Nobel Prize': How experienced examiners assess research theses. Studies in Higher Education, 27(4), 369-386.

Nightingale, P. (1984). Examination of research theses. Higher Education Research and Development, 3(2), 137-150.

Nkemleke, D. A. (2011). Exploring academic writing in Cameroon English: A corpus-based perspective. Gottingen: Cuvillier Verlag.

Pitkethly, A. \& Prosser, M. (1995). Examiners' comments on the international context of PhD theses. In C. McNaught \& K. Beattie (Eds.) Research into higher education: Dilemmas, directions and diversion (pp.129-36). Melbourne: HERDSA.

Prieto, E., Holbrook, A., \& Bourke, S. (2016). An analysis of PhD examiners' reports in Engineering. European Journal of Engineering Education, 41(2), 192-203.

Ridley, D.M. (2011). The literature review: A step-by-step guide for students ( $2^{\text {nd }}$ ed.) London: Sage.

Sankaran, S., Swepson, P., \& Hill, G. (2005). Do research thesis examiners need training? practitioner stories. The Qualitative Report, 10(4), 817-835.

Starfield, S., Paltridge, B., McMurtie, R., Holbrook, A., Lovat, T. Kiley, M., \& Fairbairn, H. (2017). Evaluation and instruction in $\mathrm{PhD}$ examiners' reports: How grammatical choices construe examiner roles. Linguistics and Education, 42, 53-64.

Stracke, E. (2010). Undertaking the journey together: peer learning for a successful and enjoyable PhD experience. Journal of University Teaching \& Learning Practice, 7(1).

Stracke, E., \& Kumar, V. (2010). Feedback and self-regulated learning: Insights from supervisors and PhD examiners' reports. Reflective Practice, 11(1),19-32.

Tinkler, P., \& Jackson, C. (2000). Examining the doctorate: Institutional policy and the PhD examination process 
in Britain. Studies in Higher Education, 25(2),167-180.

Van Wyk, C., \& Lumadi, M.W. (2009). Learning from external examiners about the application of critical research skills. International Journal of Education Science, 1(2), 91-98

Winter, R., Griffiths, M. \& Green, K. (2000). The 'academic' qualities of practice: What are the criteria for a practice-based Ph.D.? Studies in Higher Education, 25(1), 25-37. 
Afful, J. B. A., \& Tetteh, G.

26 Consortia Academia Publishing (A partner of Network of Professional Researchers and Educators) 